\title{
Multiscale Multifactorial Approaches for Engineering Tendon Substitutes
}

\author{
Ana I. Gonçalves, Márcia T. Rodrigues, Ana M. Matos, \\ Helena Almeida, Manuel Gómez-Florit, Rui M. A. Domingues, and \\ Manuela E. Gomes
}

\section{Contents}

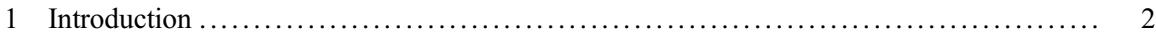

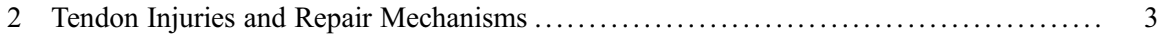

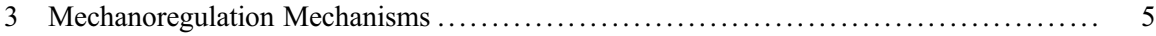

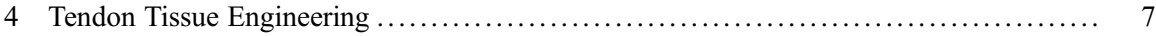

4.1 Challenges of Cell-Based Approaches ................................ 7

4.2 Biomaterial Approaches for Tendon Tissue Engineering $\ldots \ldots \ldots \ldots \ldots \ldots \ldots \ldots \ldots \quad 8$

4.3 Role of Biological Cues in Tendon Tissue Engineering Strategies ............. 13

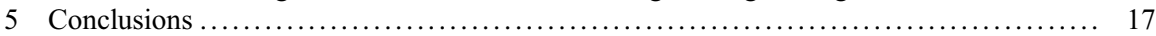

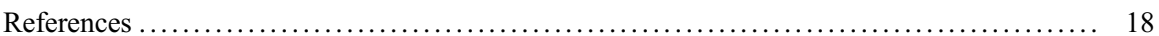

\section{Abstract}

The physiology of tendons and the continuous strains experienced daily make tendons very prone to injury. Excessive and prolonged loading forces and aging also contribute to the onset and progression of tendon injuries, and conventional treatments have limited efficacy in restoring tendon biomechanics. Tissue engineering and regenerative medicine (TERM) approaches hold the promise to provide therapeutic solutions for injured or damaged tendons despite the challenging cues of tendon niche and the lack of tendon-specific factors to guide cellular responses and tackle regeneration. The roots of engineering tendon substitutes lay in multifactorial approaches from adequate stem cells sources and environmental stimuli to the construction of multiscale 3D scaffolding systems.

\footnotetext{
A. I. Gonçalves · M. T. Rodrigues · A. M. Matos · H. Almeida · M. Gómez-Florit · R. M. A. Domingues · M. E. Gomes $(\bowtie)$

3B's Research Group, I3Bs - Research Institute on Biomaterials, Biodegradables and Biomimetics, University of Minho, Headquarters of the European Institute of Excellence on Tissue Engineering and Regenerative Medicine, Barco/Guimarães, Portugal
}

ICVS/3B's-PT Government Associate Laboratory, Braga/Guimarães, Portugal e-mail: ana.goncalves@i3bs.uminho.pt; mrodrigues@i3bs.uminho.pt; amfmatos@gmail.com; helena-mca@hotmail.com; mgflorit@i3bs.uminho.pt; rui.domingues@i3bs.uminho.pt; megomes@i3bs.uminho.pt 
To achieve such advanced tendon substitutes, incremental strategies have been pursued to more closely recreate the native tendon requirements providing structural as well as physical and chemical cues combined with biochemical and mechanical stimuli to instruct cell behavior in 3D architectures, pursuing mechanically competent constructs with adequate maturation before implantation.

Tendon is composed mainly of water ( $70 \%$ of dry weight) and a solid matrix ( $30 \%$ of dry weight) (Sharma and Maffulli 2005) mostly of collagen (70-80\%), which is the force-transmitting unit of tendon (Magnusson et al. 2003; de Aro et al. 2012). Collagen type $I$ is the main type of collagen within tendons $(95 \%$ of total collagen and $60-85 \%$ of matrix dry weight (Screen et al. 2015)) followed by collagen type III and collagen type $\mathrm{V}$. The alignment of collagen type $\mathrm{I}$ is recognized as the principal structural feature of healthy tendons (Lipman et al. 2018). Together with collagen type I, type V, and type XI, collagen type III is a fibril-forming collagen and widely distributed in collagen I containing tissues. Upon injury, collagen type III increases. This has been associated to its rapid cross-linking contributing to stabilize the repair site and to the remodeling process of the matrix highlighting the importance of collagen type III in tendon healing processes. However, collagen type III forms smaller and less organized fibrils than the ones of collagen type I. Abundant collagen type III results in a tendon with inferior mechanical properties, which has been related to a degenerative process (Millar et al. 2015). Collagen type V is important for regulation and stabilization of collagen type I structures during self-assembly (Wenstrup et al. 2004), while collagen type VI regulates collagen I fibrillogenesis to form a functional and mature tendon (Izu et al. 2011).

Tendons are mainly composed of tenoblasts and tenocytes approximately 90$95 \%$ of tendon cells (Schneider et al. 2017) whose major function relies in the synthesis and maintenance of the tendon extracellular matrix. Tenoblasts are roundly shaped cells with a large, ovoid nucleus that mature to spindle-shaped tenocytes with elongated nuclei in response to mechanical regulators and to growth factors during tendon development. These cells are discriminated based on morphology; however, precise identification based on specific markers is still lacking. Nevertheless, there are tendon-associated markers that may assist the establishment of tenogenic protocols and offer new perspectives for studying tendon biology.

The transcription factor scleraxis (Scx) is expressed from immature to fully differentiated stages of tendon cells. Other factors, namely, Mowahk (Mwk), Egr1, and Egr2 are detected at the stage of tenoblasts. Both tendon-progenitor cells and tenoblasts also express collagen I, Tenascin (TNC), Thrombospondin (Thbs4), and Tenomodulin (Tnmd). Mature tenocytes typically express Scx and Mwk as well as Egr1 and Smad3. Developmental and in vitro studies have been pointing Scx and Mwk as tendon-specific factors despite the fact they can be detected in other tissues. The ECM matrix produced by tenocytes is rich in collagen I, III, V, and XIV; Decorin; Fibromodulin; Lumican; and Tnmd. 
The tenocytes are organized in longitudinal rows between collagen fibers and respond to mechanical forces. These cells establish communication with adjacent cells usually through connexins 26,32 , and 43 in gap junctions. Tendon cell activity declines with age leading to unbalanced processes thus contributing to tissue degeneration and to incremental severity of injuries.

More recently, stem progenitor cells (TSPCs) were identified in tendons shown to possess regenerative capabilities (Salingcarnboriboon et al. 2003; Bi et al. 2007; de Mos et al. 2007; Zhang and Wang 2010). TSPCs exhibit the typical surface antigens of adult mesenchymal stem cells (MSCs), self-renewal, clonogenicity, and tri-lineage differentiation, fitting the classical MSCs criteria, and highly express tendonspecific factors, namely, Scx and Tnmd (Bi et al. 2007).

Paratenon, epitenon, and endotenon are the non-tenogenic components of tendons. The paratenon allows tendon to move freely and continues to the fascia, while epitenon is defined as a dense connective tissue sheath covering tendon. Both are vascularized and enervated. Endotenon is formed by collagen fibers surrounding the tertiary fascicles of the tendon. Not all tendons are sheathed by paratenon although there is evidence of its involvement in tendon healing (Dyment et al. 2013; Muller et al. 2018).

During the last decade, tremendous effort has been done pursuing the key features of tendon niches to recapitulate tendon biology enabling the identification of specific tissue requirements guiding the mechanisms underlying healing and regeneration phenomena. Undoubtedly, the mechanical forces applied to tendons are critical for the maintenance of the homeostasis in healthy tendons, and that misuse or overuse can deregulate the physiological balance inflicting pathological alterations at a biomolecular and cell levels, thus contributing to impaired healing and abnormal tissue functionality. Understanding how mechanical forces regulate (stem) cell behavior and matrix features may provide key insights on tendon biology and assist the development of regenerative therapies (Vining and Mooney 2017).

This chapter overviews tendon engineering approaches to mimic tendon niches envisioning sophisticated alternatives to stimulate tendon healing and regenerative processes, anticipating functional contributions for improved tendon-oriented therapies and treatments.

\section{Tendon Injuries and Repair Mechanisms}

Along with the socioeconomic burden, tendon pathologies are a significant cause for disability for both working and ageing populations. The incidence of tendon injuries is rising and becoming a paramount problem without effective therapeutics. Despite tendons are designed to withstand mechanical forces, they are prone to lesions that aggravate with the time, compromising articular performance and the quality of movements and physical activities. Damage in the joint may eventually lead to morbidity, pain, and osteoarthritis (Wang et al. 2012). Although genetic predisposition factors make individuals more or less susceptible to injury (Riley 2004; Rees et al. 2006; Docheva et al. 2015), tendons become more prone to degeneration and to 
injuries with advanced stages of life. Moreover, aging and age-related pathogenesis are also associated to impaired healing, presenting a huge opportunity to address the unmet needs for new therapies and customized treatments for tendon diseases.

Excessive mechanical loading resulting from small repetitive strains may lead to accumulation of tendon microinjuries (Soslowsky et al. 2000; Willett et al. 2007) contributing for the progression of tendinopathic conditions. Tendinopathy typically defines a non-rupture injury in the tendon or paratenon, which is exacerbated by mechanical loading and typically accompanied by pain/swelling of injured tendon. Pain and functional limitation are frequent symptoms conventionally treated with nonsteroidal anti-inflammatory drugs (NSAIDs), corticosteroids, and physical rehabilitation. However, the prolonged systemic action of these drugs has been reported to cause significant long-term side effects as changes in blood pressure, myocardial infarction and strokes, increased bleeding, osteoporosis, or peptic ulcers. The more severe cases typically require surgical intervention, which rely on tissue replacement with auto- or allografts (Rodrigues et al. 2013). However, these are often accompanied with donor site morbidity, pain, inferior functionalities, and eventually graft failure. The limited long-term success of surgical procedures compromises tendon functionality impacting the quality of life of patients.

The healing capacity of tendons varies according to severity of injury and anatomical location, and it is classically divided in three main stages. The first stage is a short inflammatory phase that initiates after injury. The vascular permeability increases as well as the influx of inflammatory cells (platelets, macrophages, monocytes, and neutrophils) to the site of injury. These cells release chemotactic agents responsible for the recruitment of blood vessels, fibroblasts, and intrinsic tenocytes that together with inflammatory cells form a hematoma (Lin et al. 2004). As part of the inflammatory response, macrophage phagocyte injured tissue fragments and has an important role on tenocytes proliferation and angiogenesis (Woo et al. 1999). The second stage is characterized by an abundant proliferation of tenocytes at the site of injury with concomitant production of collagen. This phase lasts from a few days to a couple of weeks. The remodeling phase is the third and final stage and can last several months (Sharma and Maffulli 2005). The extracellular matrix is reorganized with a gradual change in the direction of collagen fibers from fibrous to scar-like tissue accompanied by a cellular decrease and reduction of vascular vessels (Sharma and Maffulli 2006).

Tendon healing was traditionally described to be intrinsic or extrinsic in nature. The intrinsic process was mediated by tenocytes from epitenon and endotenon, and the repaired tissue evidenced higher mechanical properties and fewer complications. Extrinsic healing was dependent on cell migration from adjacent tissues resulting in scar tissue leading to adhesions formation (Sharma and Maffulli 2005; Zhao et al. 2015). Although the repair process depends on the anatomy and physiology of each tendon, tendon healing is now described to occur from the interplay of local tendon cells and external cells, including immune, vascular, synovial, and mesenchymal stem cells.

Understanding and modulating the mechanisms underlying healing will allow more effective treatments and rehabilitation. Moreover, as a key process in tendon 
tissues, insights tendon healing and the research of tendon mechanobiology will likely contribute to advanced clinical solutions resourcing to tissue engineering and regenerative medicine strategies.

\section{Mechanoregulation Mechanisms}

As mechanosensitive and mechanoresponsive tissue, the main function of tendon is transmitting tensile loads that varies with the anatomical location and can reach to several tens of megapascal (MPa). This incredible feature of tendons is extremely dependent on its structure and cellular organization, and it is critical for the proper function of joints (Killian et al. 2012; Lavagnino et al. 2015). The unique structure and composition confer tendon a characteristic mechanical behavior which is classically described in a stress-strain curve (Fig. 1). The initial "toe" region represents the flattening of crimp pattern when tendon is strained up to $2 \%$. In the linear region, tendon is stretched up to $4 \%$, and collagen fibers lose the crimp pattern. Altogether, these regions represent the physiological response of tendon. If tendon is stretched more than $4 \%$, a microscopic failure of collagen fibers occurs. However, when the

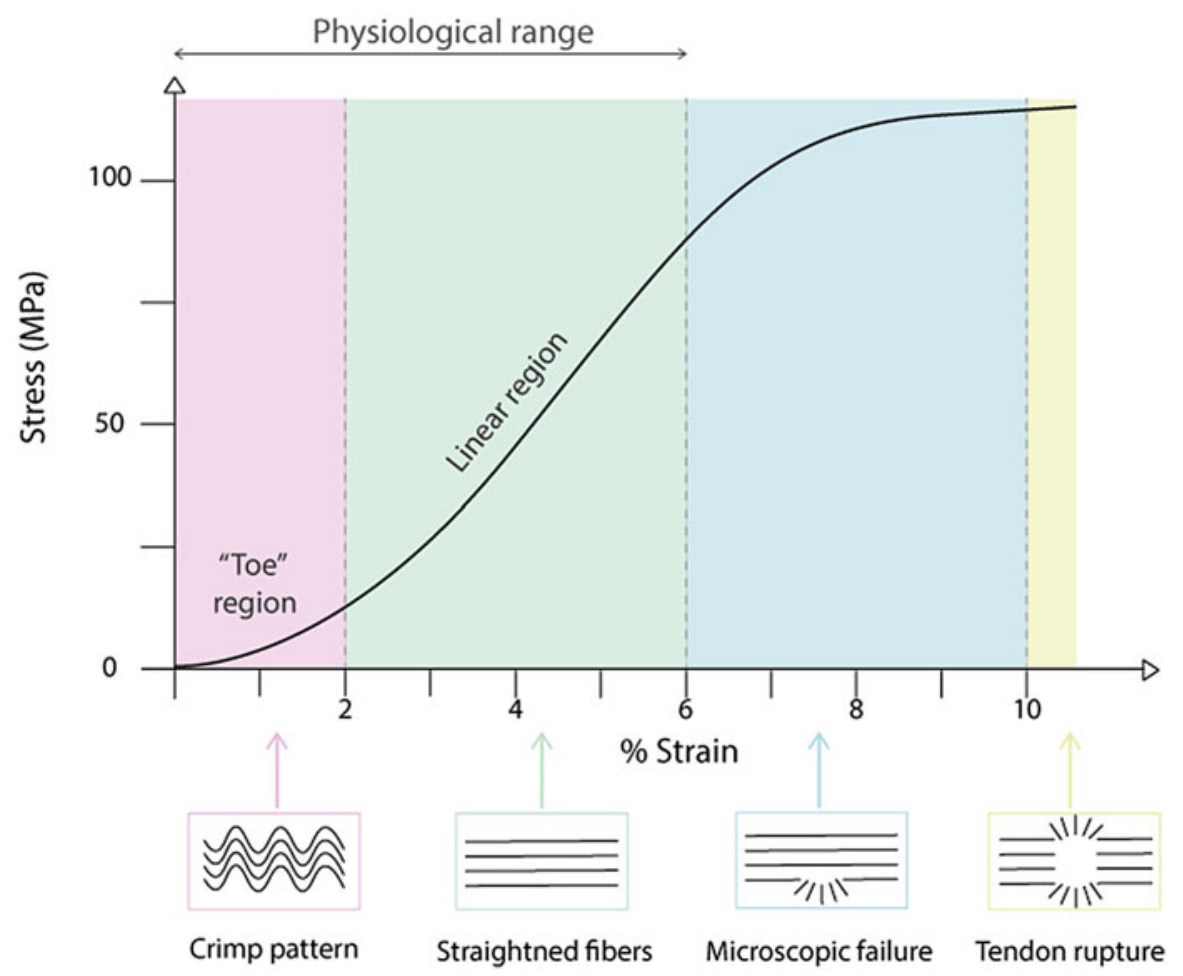

Fig. 1 Typical stress-strain curve of tendon tissues exposed to increasing mechanical loads 
forces applied are below this value, tendon remains in the elastic zone and can return to its original shape when a load is removed. Macroscopic failure of collagen fibers is observed in loads between 8 and $10 \%$, while rupture of collagen fibers is verified with mechanical loads higher than $10 \%$.

Thus, the sensing of mechanical forces by the cells and further translation of the cellular response to microenvironmental cues is of utmost importance in deciphering precise mechanisms of action toward tenogenic recipes and opens avenues of research seeking to develop efficient therapies.

Mechanotransduction is the ability of cells to respond to mechanical stimuli through biochemical signals (Santos et al. 2015) being important to maintain musculoskeletal tissue development, homeostasis, repair, and regeneration (Wang 2006). Cells are able to sense distinct mechanical stimulus within the matrix and to respond accordingly and rapidly by adjusting physical ligands or rearranging its cytoskeleton. These adjustments affect the perception of loading in the mechanosensory elements of cells, present in the cellular membrane and nucleus.

Signaling cascades are the main routes of communication between the membrane and intracellular regulatory targets. The two main signaling pathways identified as being involved in tendon development are TGF $\beta$-SMAD2/3 and FGF-ERK/MAPK pathways (Havis et al. 2014a). FGF signaling from the myotome was firstly associated to induction of $S c x$-expressing tendon progenitors in adjacent somatic subcompartment of developing axial tendons in chick (Brent et al. 2003).

Interestingly, in pharmacologically immobilized chick embryos, both FGF and TGF- $\beta$ signaling cascades were downregulated, suggesting that FGF and TGF- $\beta$ ligands regulate tendon differentiation acting downstream to mechanical forces present in developing embryo (Havis et al. 2016).

In mammalians, there are three isoforms of TGF- $\beta$, and all are involved in tenogenic differentiation. Studies reported that in the presence of TGF- $\beta 1$ the expression of Scx and Mkx is highly upregulated (Farhat et al. 2012), and the decline of mechanical properties was significantly hindered (Katsura et al. 2006). The isoform TGF- $\beta 2$ increased the expression of Collal and Scx genes (Havis et al. 2014b; Liu et al. 2015), while TGF- $\beta 3$ promoted tendon differentiation of equine embryo-derived stem cells (Barsby and Guest 2013). Furthermore, TGF- $\beta 3$ was suggested to be an essential element of a recently proposed tenogenic differentiation cocktail (Stanco et al. 2019).

Generally, in a signaling cascade, the ligand requires two types of serine/threonine kinases receptors, a type I and a type II that form a receptor complex. Some ligands require additional co-receptors for binding between the ligand and the complex receptor. In the receptor complex, the cytoplasmic domain of the type II receptor is active and phosphorylates the type I receptor on serines and threonines in a highly conserved glycine- and serine-rich domain, neighboring the region that crosses the membrane. The activated type I receptor supplies a ligand binding site for the downstream substrates, the receptor-regulated SMADs (R-SMADs) that will transduce the signal to the nucleus (Wrighton et al. 2009; Wakefield and Hill 2013). The TGF- $\beta$ s, activins, and NODAL signal through SMAD2 and SMAD3 (Wakefield and Hill 2013; Zhang et al. 2018a). In humans, there are seven type I 
receptors known as activin receptor like-kinases (ALK) each being responsible to regulate the phosphorylation of different R-SMADs. ALK1, ALK2, ALK3, and ALK6 phosphorylate SMAD1, SMAD5, and SMAD8, while ALK4, ALK5, and ALK7 phosphorylate SMAD2 and SMAD3 (Schmierer and Hill 2007).

Furthermore, the synergistic effect of mechanical stimulation and the activation of TGF- $\beta /$ SMAD2/3 cascade has an important role on the regulation of mechanical and biochemical signaling pathways that regulate $S c x$ expression (Maeda et al. 2011; Goncalves et al. 2018b).

\section{$4 \quad$ Tendon Tissue Engineering}

\subsection{Challenges of Cell-Based Approaches}

Tendon tissue engineering has been challenged by a significant lack of understanding in the identification and characterization of tendon niches. As functional living entities, cells are of critical importance on the interplay of biological responses leading to tissue repair and regeneration. Despite the growing knowledge, the precise culture conditions and environment cues to stimulate tendon resident cells and guide cell fate require further developments.

In 2007, $\mathrm{Bi}$ et al. reported a novel stem/progenitor cells (TSPCs) population within the tendon fascicle ( $\mathrm{Bi}$ et al. 2007). Despite the efforts, the origin of resident tendon-progenitor/stem cells and the factors that influence their differentiation is still poorly understood, compromising the design and development of novel repair and regenerative strategies.

TSPC subsets have been identified in peritenon (Cadby et al. 2014; Mienaltowski et al. 2014) holding unique signatures yet both capable of tenogenic differentiation and forming collagen-rich structures (Cadby et al. 2014, Mienaltowski et al. 2014). Mienaltowski MJ et al. reported that stem cells from tendon proper are more suited for regeneration of tendon structure, while stem cells from peritendon secreted tendon-promoting factors that bolster expression of tendon markers in tendon proper stem cell and tenocytes (Mienaltowski et al. 2014). Cadby JA et al. observed that cells from the peritenon migrated faster replicate more quickly holding higher expression of progenitor cell markers (Cadby et al. 2014).

Within paratenon tissues, fibroblastic, vascular, synovial, neural, and fat cells may be detected. TSPC subsets expressing vascular (Mienaltowski et al. 2014) markers have also been described which emphases the intercellular role in homeostasis and in the healing processes. In particular, the vicinity of vascular cell populations of pericytes or perivascular cells has attracted a lot of attention in tendon biology not only because perivascular niche may be source for epitenon-derived stem cells, known to express vascular markers but the fact that extrinsic healing in tendons rely on the migration of cells from surrounding tissues, including blood vessels. These mechanisms are central to our understanding of the onset and development of tissue pathologies and to guide cellular responses with precise regenerative action. 
The origin of stem cells populations relates to distinctive signature profiles yet with complementary roles in tendon biology. Moreover, cell plasticity of tendon core and peritendinous sources may provide particular contributions for tendon repair mechanisms and for improved therapeutic solutions for tendon pathologies.

Despite the therapeutic promise of TSPCs, the limited number of local TSPC populations, especially in adult and elder patients, and the invasiveness of the harvesting procedures from a relatively hypocellular tissue can compromise their availability and use in the clinical practice. Moreover, local cell sources require the patient to wait for cell expansion procedures until a suffice number of cells is achieved for implantation. Thus, alternative cell sources have been investigated for tissue engineering and regenerative medicine strategies. Mesenchymal stem cells from bone marrow and adipose tissue are heterogeneous sources described not to incite immunologically adverse responses or to raise ethical constrains as pluripotent stem cells (ESCs and iPSCs) and have been pursued for tenogenic phenotype with evidence of improving tendon healing in in vivo models of tendon injuries (Gonçalves et al. 2013; Shen et al. 2018). Unlike TSPCs, bone marrow and adipose tissue-derived stem cell sources are considerably available and have recognized potential to be used for the regeneration of different types of tissues including tendons (Yin et al. 2016; Perucca Orfei et al. 2019). Tendon-oriented strategies employing non-tenogenic MSCs cultures typically rely on inductive factors to stimulate tenogenic cues such as TGF- $\beta$ (Gonçalves et al. 2013), GDF-5, and connective tissue growth factor (CTGF), despite the fact that cocktails have not been fully established (Yin et al. 2016, Perucca Orfei et al. 2019). Moreover, previous studies by our research group (Rada et al. 2011a, b, 2012; Mihaila et al. 2013, 2014, 2015; Goncalves et al. 2018a) and others (Miranville et al. 2004; Sengenes et al. 2007) show that human adipose stem cells (hASCs) are composed of subpopulations with distinct differentiation potential, which highlights the differential role of subpopulations to lineage commitment and toward tissueoriented applications. A Tenomodulin positive subpopulations demonstrated increased tenogenic differentiation potential (Goncalves et al. 2018a) when compared to the crude population and also when compared to SSEA-4+ hASCs subpopulation (Gonçalves et al. 2019).

The control over stem cell fate, either from tendinous or non-tendinous tissues for cell-based therapies or as part of a multiscale approach offers new possibilities into improved healing and treatment intervention of tendon pathologies. However, finding tendon-specific markers enabling standardization of protocols and proper characterization of the cellular roles within tendon tissues are still unmet features to be addressed in the following years.

\subsection{Biomaterial Approaches for Tendon Tissue Engineering}

Tendon TE strategies where the tenogenic niche is being mimicked are prone to induce a more adequate response regarding cell phenotype and fate. Different studies have emerged in this field in which several aspects of tendons' ECM structure and composition were recapitulated into mechanically competent constructs and cell behavior assessed, aiming to induce endogenous tissue repair. 


\subsubsection{Fibrous Scaffolds for Tendon Tissue Engineering}

Two- and three-dimensional (2D and 3D) structures designed to resemble native tendons have been developed over the years (Chainani et al. 2013). Attending to their architecture, some authors developed systems mainly based on fibrous scaffolds where the fiber diameter, alignment, and overall stiffness were considered as topographic beacons to guide cell fate. Others valued the mechanical demand these tissues are subjected to and considered mechanical stimulation.

\section{Strategies Involving Topographic Cues}

Concerning 2D systems, these are mostly developed to evaluate how different stimuli influence cell behavior, once they usually lack appropriate mechanical properties for potential clinical application (Spanoudes et al. 2014, Santos et al. 2017). Fiber diameter and alignment have been proven to modulate cell's behavior conjointly. Systems with topographic cues in the nanoscale seem to be more effective in allowing cell growth and synthesis of glycosaminoglycans (GAGs) and collagen overtime, in either random 4 or aligned (Erisken et al. 2013a; Lee et al. 2017) conformations. Micro-cues, on the other hand, have been shown to suppress cell growth and collagen synthesis (Gilchrist et al. 2014; Lee et al. 2017).

Regarding cell morphology, both tendon cells (Erisken et al. 2013b; English et al. 2015) and MSCs (Bashur et al. 2009) present higher cell aspect ratio when exposed to substrates with microfeatures compared to nanocues (Yu et al. 2013). Additionally, anisotropic constructs are more prone to induce the tenocyte-like spindle-shape morphology and alignment along nanofibers' axis in the seeded cells, as opposed to the arbitrarily oriented cell morphologies acquired in random substrates (Moffat et al. 2009; Xie et al. 2010). Nonetheless, grooves' depths as small as $40 \mathrm{~nm}$ did not induce tenocyte alignment despite their parallel organization, suggesting that there is a minimum size cells can perceive (English et al. 2015). Accordingly, Domingues et al. used a solution of poly- $\epsilon$-caprolactone (PCL) and chitosan (CHT) reinforced with rod-shape nanofillers, cellulose nanocrystals $(\mathrm{CNCs})$, to produce random and aligned meshes through electrospinning with increased mechanical properties. Tenocytes seeded onto the anisotropic constructs maintained their elongated phenotype with aligned arrangement, as opposed to the cells on the random meshes (Domingues et al. 2016).

Furthermore, the expression of tendon-related markers as Scx, Tnmd, ColI, and Mkx by stem cells is enhanced in aligned surfaces, indicating that tenogenesis is encouraged, while in randomly oriented membranes, osteogenic genes are upregulated (Zhang et al. 2015). Schoenenberger et al. also correlated substrate alignment with ECM turnover, demonstrating that tendon cells on PCL random nanomats are polygonal and show decreased Mkx, ColI, and ColIII expression getting further from a tenogenic profile, as well as decreased MMP1 suggesting less matrix remodeling, as opposed to aligned constructs (Schoenenberger et al. 2018).

Submicron 2D systems typically display limited dimensions and pore size, do not respond properly to the mechanical demand necessary to support tendon healing, and are generally too weak to be surgically implanted (Barber et al. 2013; Hakimi et al. 2015; Zheng et al. 2017). Thus, 3D systems that mechanically sustain tissue 
regeneration and mimic tendon architecture have been considered (Santos et al. 2017). By stacking multiple electrospun PCL aligned membranes, clinically relevant sized constructs can be generated, allowing hASCs infiltration, alignment, and higher Tnmd and ColIII expression than random multilayered scaffolds. In addition, the tensile mechanical properties are improved upon cell seeding for anisotropic constructs (Orr et al. 2015).

Mimicking the native tendon highly anisotropic and hierarchic architecture has been a research priority (Brennan et al. 2018). Textile techniques, as braiding, twisting, and weaving, enable the construction of $3 \mathrm{D}$ tendon scaffolds of incremental organization and mechanical performance, from threads or yarns (Freeman et al. 2007, Czaplewski et al. 2014, Santos et al. 2017). Electrochemically aligned collagen (ELAC) threads have shown to induce tenogenic differentiation of human MSCs, unlike random collagen threads, evidenced by the superior expression of Scx, Tnmd, TNC, and ColIII, accompanied by enhanced ECM deposition and alignment (Kishore et al. 2012). When assembled into yarns, these natural-based woven textiles exhibited a significant increase in their mechanical properties, reaching an average tensile Young's modulus between 500 and $600 \mathrm{MPa}$ and ultimate tensile strength (UTS) of 60-70 MPa, within the range of the native tendon (Younesi et al. 2014). Additionally, the yarns maintained their tenoinductive ability, with MSCs showing an increased expression of Tnmd and Coll overtime, parallel to the inhibition of osteogenic markers (Kishore et al. 2012).

Following the same principle, Laranjeira et al. recreated the nano-to-macro hierarchical and anisotropic structure of the native tendon by assembling woven scaffolds of continuous and aligned electrospun nanofibrous threads, made of PCL and CHT mechanically reinforced with CNCs (Domingues et al. 2016). The weaved structures exhibited the native tendon nonlinear mechanical behavior with evidenced toe region. The woven scaffolds presented a Young's modulus smaller than $200 \mathrm{MPa}$ and UTS of approximately $40 \mathrm{MPa}$, whereas the yarn 12 of 300-400 $\mathrm{MPa}$ and $60 \mathrm{MPa}$, respectively (Laranjeira et al. 2017). As outcome, these structures not only avoided the tenogenic phenotypic drift of human tenocytes but also triggered the tenogenic differentiation of hASCs without biochemical supplementation, increasing the expression of tendon-related markers TNC and SCX.

\section{Strategies Involving Mechanical Stimulation}

Besides topographic cues, cells are sensitive to applied mechanical forces within the physiological range, capable of modulating their lineage commitment and ECM biosynthesis and degradation (Wang et al. 2013; Gonçalves et al. 2018). Tendons high physical demand and mechanosensitive behavior led to the development of bioreactors as exogenous sources of mechanical stimulation, to recapitulate the in vivo microenvironment native cells are exposed to (Wang et al. 2013; Spanoudes et al. 2014; Gonçalves et al. 2018).

Subramony et al. assessed the role of nanofiber alignment and mechanical stimulation on MSCs differentiation, in the absence of biochemical supplementation, using electrospun unaligned and aligned poly(lactide-co-glycolic acid) (PLGA) nanofibrous membranes, placed on a bioreactor that applied uniaxial tensile strain. 
The authors stated that tenogenic differentiation was induced on aligned substrates with load application, whereas loading nonaligned scaffolds or exposing cells just to aligned substrates did not induce proper differentiation, reinforcing the importance of mechanical stimulation (Subramony et al. 2013).

Nonetheless, the use of bioreactors faces some shortcomings, as the inability to use upon implantation and the cell impairment that may result from their physical presence in culture environments (Riehl et al. 2012). Therefore, scaffolds incorporating magnetic responsiveness, which can be remotely actuated by the application of an external magnetic field, allowing cell guidance and stimulation following implantation have been recently developed (Goncalves et al. 2016). Considering this, Tomás et al. used the setup proposed in a previous study (Laranjeira et al. 2017) to produce yarns of continuous and aligned electrospun threads of PCL and CNCs coated with iron oxide magnetic nanoparticles (MNPs) (Fig. 2). Cell studies revealed that hASCs express tendon-related genes both in static and dynamic conditions after 11 days of culture (Tomás et al. 2019), in agreement with previous studies (Laranjeira et al. 2017; Almeida et al. 2019). Furthermore, mechanical stimulation lead to marked upregulation of Scx and Tnmd at the gene and protein levels (Fig. 2) and downregulation of Runx2, suggesting a synergistic effect of nanotopography and mechanical actuation on the tenogenic commitment.

\subsubsection{D Printing for Tendon Tissue Engineering}

Over the past decade, 3D printing has evolved from layer-by-layer deposition of materials to fabricate 3D scaffolds to bioprinting, which allows patterning and assembly of cells and materials with a defined 3D organization to produce bioengineered structures serving in regenerative medicine, pharmacokinetics, and basic cell biology studies. Although there are many promising examples of the application of this technology in various tissue engineering and regenerative medicine strategies (Bracaglia et al. 2017; Lim et al. 2017; Derakhshanfar et al. 2018; Moroni et al. 2018a, b), its use for the fabrication of tendon TE scaffolds is a field under development, and very few studies have been published. One of the first works in the field was developed by Merceron et al. to fabricate a muscle-tendon unit construct (Merceron et al. 2015). The combination of polymeric materials to print the structural component with cell-laden bioink to print the cellular component resulted in customizable hybrid/multimaterial constructs with anisotropic patterns, mimicking tendon and muscle characteristics. Thermoplastic polyurethane (PU) and $\mathrm{C} 2 \mathrm{C} 12$ myoblasts were used for the muscle side and PCL and NIH/3 T3 fibroblasts for the tendon side. These constructs showed over $80 \%$ cell viability 1 week after printing, and the cell organization was consistent with the native tissue interface. In a more recent study, 3D musculoskeletal-tendon-like tissues were printed alternating layers of gelatin methacryloyl and cells (tenocytes and myoblasts) around and between posts created in a culture well, envisioning a screening platform. The cells showed high viability in culture and tissue differentiation markers (Laternser et al. 2018).

The development of a magnetic scaffold by $3 \mathrm{D}$ printing for tendon tissue applications was described by us (Goncalves et al. 2016), based on a polymeric blend of starch and PCL (SPCL) incorporating magnetic nanoparticles. The purpose was to 


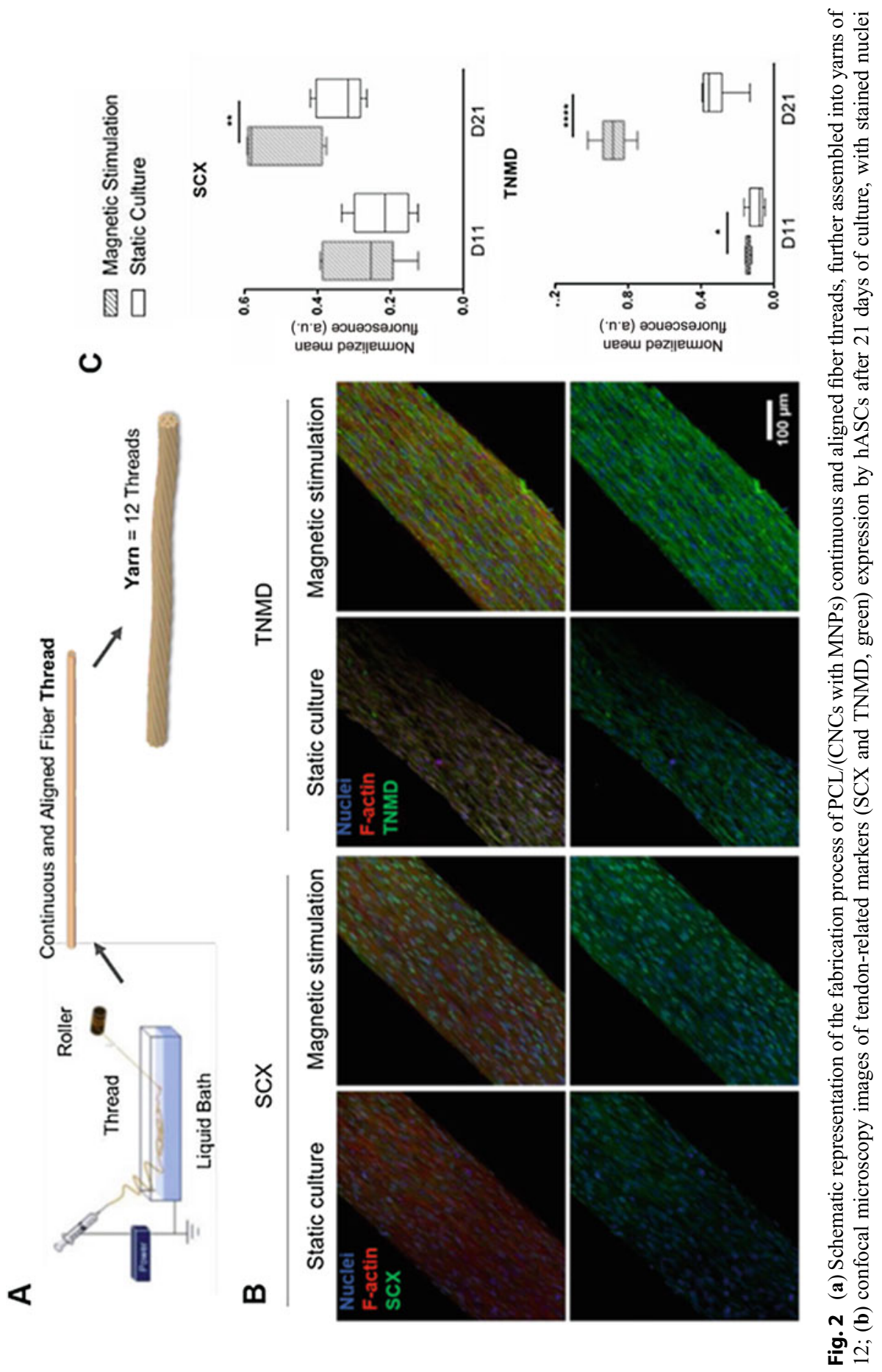


combine structural features of the 3D scaffold with mechanomagnetic actuation to study the differentiation of hASCs to the tenogenic phenotype and assist tendon regeneration. The anisotropic scaffolds promoted the tenogenic differentiation of hASCs under magneto-stimulation with evidence of good biocompatibility and integration in an ectopic rat model (Goncalves et al. 2016). In a different strategy, anticipating patient-specific therapies, 3D printed scaffold sleeves made of PCLPLGA- $\beta$-TCP were developed considering the size and shape of the tendon and bone tunnel. Then, these scaffolds were seeded with MSCs and tested in vivo for up to 12 weeks in an anterior cruciate ligament (ACL) reconstruction model in rabbits (Park et al. 2018). The construct enhanced osteointegration between the tendon and tunnel bone in the ACL reconstruction (Park et al. 2018).

\subsection{Role of Biological Cues in Tendon Tissue Engineering Strategies}

Substrates providing instructive cues through cell-surface contact guidance have been associated with biochemical signals to add functionality, creating microenvironments for cell differentiation that closely resemble native tissues (Santos et al. 2017). Several bioinductive elements have been investigated as intermediaries of cell destiny, as media supplements or surface modifications (Spanoudes et al. 2014; Lin et al. 2018).

\subsubsection{Strategies Involving Medium Supplementation with Growth Factors}

Strategies based on growth factors and other small cell-signaling molecules have emerged in the context of tendon tissue regeneration. These have been identified as potent modulators of cell fate, acting on chemotaxis, proliferation, matrix synthesis, and/or differentiation (Baldwin et al. 2018; Dalby et al. 2018).

TGF- $\beta 3$ is a modulator of tenocyte function and tendon development, since its signaling is known to induce the expression of Scx, a potent tenogenic marker (Leung et al. 2013). When used as a medium supplement in combination with aligned PCL/CHT meshes, TGF- $\beta 3$ has a synergistic effect on the expression of tenogenic markers by BM-MSCs, suggesting that its individual action cannot trigger the lineage commitment as structural cues do, but helps in tenocyte maturation (Leung et al. 2013). Therefore, this growth factor is often used as a component of tenogenic differentiation medium (Yang et al. 2016; Rothrauff et al. 2017; Wu et al. 2017). Accordingly, Yang et al. studied the combined effect of native tendon-derived ECM obtained from decellularized tissues with TGF- $\beta 3$ on the tenogenic

Fig. 2 (continued) (blue) and actin filaments (red). Scale bar: $100 \mu \mathrm{m}$; and (c) normalized mean fluorescence intensity quantification of SCX and TNMD. Adapted from Tomás et al. (2019) with permission from the Royal Society of Chemistry 
commitment of hASCs. They observed that on tissue culture plastic, the dual action of TGF- $\beta 3$ and decellularized tendon ECM markedly enhanced the expression of Scx and Tnc when compared to their individual effect. Furthermore, this same trend was observed on PCL aligned scaffolds (Yang et al. 2017). Moreover, hASCs seeded in decellularized tendon ECM-supplemented collagen gels showed upregulation of tendon-related genes and downregulation of bone-related genes, in comparison to pure collagen scaffolds (Yang et al. 2013).

A different approach was considered by Engebretson et al. that used tendon lysates as a form of supplementation together with cyclic mechanical stimulation of human umbilical vein scaffolds with seeded MSCs. The tendon lysates used in a static system increased the expression of tendon-related genes more than in nonsupplemented conditions, while when associated with cyclic mechanical stimulation, it resulted in tissue enhanced tensile strength and fibril alignment, as in the native tissue (Engebretson et al. 2017).

Several studies have demonstrated the positive impact of bone morphogenetic protein-12 (BMP-12) on the tenogenic differentiation of MSCs and tissue healing (Shen et al. 2013; Dale et al. 2018). Aligned gelatin methacryloyl/alginate yarns loaded with BM-MSCs were exposed to static mechanical stretching and BMP-12 supplementation both independently and simultaneously (Rinoldi et al. 2019). This combination enhanced stem cells tenogenic commitment although it inhibited collagen gene expression (Rinoldi et al. 2019).

\subsubsection{Biofunctionalization of Scaffolds with Growth Factors}

Growth factors may present a very quick inactivation and short half-life when used as medium supplements (Sahoo et al. 2010; Font Tellado et al. 2018). Therefore, systems in which these therapeutic agents are incorporated for in situ action and gradual delivery while ensuring their biological activity and stability hold numerous advantages.

Knitted silk scaffolds coated with (FGF-2)-releasing ultrafine PLGA promoted superior MSCs viability and proliferation although its role on tenogenesis was not fully assessed (Sahoo et al. 2010). Likewise, tenocytes cultured on braided PCL/ collagen-FGF-2 scaffolds exhibited enhanced proliferation and expression of COLI, COLIII, and TNC, and scaffolds subjected to dynamic stimulation and further implanted in vivo enabled the deposition of aligned collagen after 12 weeks (Jayasree et al. 2019).

The conjugation of connective tissue growth factor (CTGF) in hierarchically electrospun scaffolds encouraged the proliferation of MSCs and the deposition of COLI and III in vitro and in vivo; however stem cell differentiation was not completely evaluated (Pauly et al. 2017). Even though CTGF has been positively correlated with tendon regeneration, further studies should be conducted to better understand its influence on tenogenic commitment (Lee et al. 2015; Shen et al. 2018).

A PDGF delivery system was developed using PLGA-monomethoxy-poly(ethylene glycol) (PLGA-m-PEG) nanoparticles. These were then associated with collagen to form aligned fibers through an electrochemical process. The alignment of the collagen fibrils resulted in increased Tnmd gene expression by hASCs, with the 
controlled release of PDGF boosting this effect and leading to higher Scx expression, in comparison with randomly oriented fibers (Cheng et al. 2014). Accordingly, hASCs seeded on porous membranes with reverse gradients of PDGF-BB and BMP-2 exhibited a tenogenesis-like behavior in the sections with higher PDGFBB and lower BMP-2 content, correspondent to the immunohistochemical observation of higher TNMD and lower bone sialoprotein expression, while osteogenesis was promoted on the inverse situation (Min et al. 2014). More recently, PDGF was immobilized on the surface of electrospun aligned structures of poly(l-lactic acid) (PLLA) through a polydopamine (PDA) coating, forming a gradient of concentrations. hASCs adhered and spread similarly along the gradient, proliferating better than in the random scaffolds. Regarding the tenogenic differentiation, these cells had the highest protein expression of SCX and TNMD in the sections with highest amount of surface-bound PGDF, gradually decreasing with lower PDGF content (Madhurakkat Perikamana et al. 2018). Both strategies are particularly interesting for tendon to bone repair.

Silk fibroin scaffolds with isotropic (bone-like) and anisotropic (tendon-like) sections were functionalized with heparin to immobilize TGF- $\beta 2$ and growth differentiation factor-5 (GDF-5). In the aligned segment, the presence of TGF- $\beta 2$ allowed the highest deposition of COLI and slightly increased ColI, Mkx, and Tnc expressions, while in the isotropic region, the expression of the chondrogenic markers Sox9, ColII, and aggrecan was upregulated in the simultaneous presence of TGF- $\beta 2$ and GDF-5, therefore unveiling new possibilities for enthesis-targeting strategies (Font Tellado et al. 2018).

Considering the reduced expression of histone deacetylases (HDACs) in native tendon stem/progenitor cells, Zhang et al. tried to enhance their tenogenesis on PLLA/poly(ethylene oxide) (PEO) aligned scaffolds using an HDAC inhibitor, trichostatin A. This small molecule incorporated on the aligned PLLA fibers led to increased mRNA expression of Scx and Mkx by TSPCs and superior SCX, COLI, COLV, and TNMD protein expression. Random fibers, on the other hand, proved to be the less efficient on TSPC tenoinduction (Zhang et al. 2018c).

\subsubsection{Biofunctionalization of Scaffolds with ECM Components}

Tendons are characterized by a scarce cell population within a very dense ECM composed of several macromolecules, each playing a distinct role on the mechanical function and biochemical signaling of the tissue (Yang et al. 2013). Hence, scaffolds' biofunctionality in terms of cell adhesion and stem cell tenogenic commitment might be enhanced with surface coatings of ECM components, to resemble the native musculoskeletal tissue (Lin et al. 2018; Jenkins and Little 2019).

Collagen, the main component of tendon's ECM, has been shown to improve the adhesion and growth of tenocytes, when used either as a bulk material (Theisen et al. 2010) or as a coating (Qin et al. 2005; Czaplewski et al. 2014). Tong et al. replicated native tendon's microenvironment, namely, surface topography and elasticity, using bio-imprinted substrates of polydimethylsiloxane (PDMS). When the surface chemistry was modified using a collagen type I coating, MSCs showed increased TNMD expression without using exogenous growth factors (Tong et al. 2012). Additional 

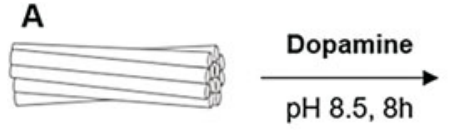

Uncoated

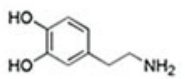

B

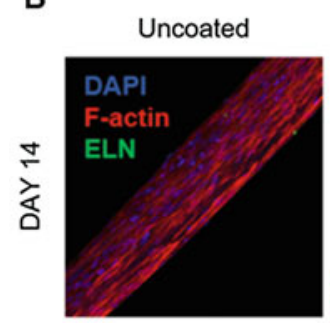

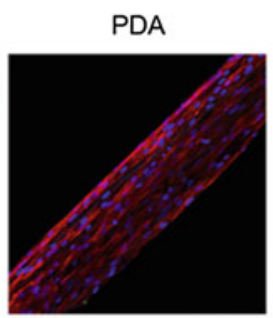

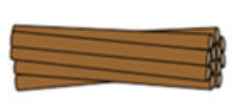

PDA
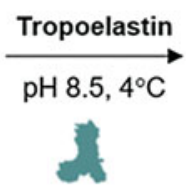

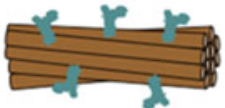

TROPO/PDA

Fig. 3 (a) Schematic representation of the general strategy to immobilize TROPO on the surfaces of yarns mimicking tendon collagen fascicles via PDA linking; and (b) confocal images of immunolabeled samples against elastin (ELN - green) expressed by hASCs after 21 days of culture, with stained nuclei (blue) and cytoskeletons (red). Scale bar for low and high magnifications: 100 and $50 \mu \mathrm{m}$, respectively. Reprinted (adapted) with permission from Almeida et al. (2019). Copyright (2019) American Chemical Society

tendon-related markers needed to be evaluated to better understand the impact on cell differentiation.

Fibronectin, another well-defined cell adhesion enhancer, has been used along with collagen in a strategy targeting to the bone-to-tendon transition (Sharma and Snedeker 2010; Lin et al. 2018). Sharma et al. evaluated the influence of both biochemical and biomechanical gradients on bone marrow stromal cells differentiation along osteogenic and tenogenic lineages. For that, hydrogels of varying stiffness at a cell length-scale (within the $\mathrm{kPa}$ range) were functionalized with collagen and fibronectin. Osteoblast differentiation was observed on the stiffer $(80 \mathrm{kPa})$ and fibronectin-coated substrates. Tenogenic markers, on the other hand, were upregulated on collagen-coated substrates with a stiffness of $40 \mathrm{kPa}$ (Sharma and Snedeker 2010). In general, softer substrates are more prone to induce tenogenic differentiation, while rigid surfaces induce the expression of chondrogenesis and osteogenic genes (Engler et al. 2006; Zhang et al. 2018b).

Elastin is another tendon ECM fibrous protein, responsible for tissue reversible recoil (Miranda-Nieves and Chaikof 2017; Jenkins and Little 2019). In a recent work, the surface of PCL/CHT/CNCs yarns (Laranjeira et al. 2017) was functionalized with tropoelastin (TROPO), the soluble precursor of elastin, through PDA linking (Fig. 3), thereby tuning its elasticity and composition to mimic the tendon native ECM (Almeida et al. 2019). Upon the decrease of surface stiffness with the incorporation of PDA and TROPO, hASCs acquired faster the tenocyte-like spindle-shape morphology and exhibited a sustained expression of Scx and Tnmd, up to 21 days of culture. Even though all conditions led to the production of a tendon- 
like ECM, immunocytochemistry data shows that only in the presence of TROPO, cells synthesized and deposited elastin creating a more mimetic matrix in comparison with the other conditions (Fig. 3) (Almeida et al. 2019).

\section{Conclusions}

The cellular interactions and mechanisms underlying tendon tissues remain to be fully elucidated, challenging strategies that would greatly benefit from the knowledge of tenogenic benchmarks as specific biomarkers for tendon cell maturation, appropriate stimuli conditions, and/or the factors leading to impaired tendon healing. As a mechanoresponsive tissue, mechanical cues are key features for tendon homeostasis and function. Several works have been emphasizing scaffolds' topographic cues and mechanical stimulation as powerful modulators of cell fate. All the proposed strategies provide insightful information about the interactions between cells and their substrates. However, these systems are often considered overly simplistic as do not consider the biological signaling present in the in vivo niche. Therefore, associating bioactive prompts to scaffolds is an increasingly trend in tendon tissue engineering.

In the years to come, cellular interactions with the different stimuli should be deeply investigated, and the spatiotemporal dynamics of cellular differentiation and tissue maturation assessed in the presence of artificial tenogenic stimuli to determine preferential rankings among conditioning factors. Another aspect to be considered in future strategies is the anatomical location of tendon tissues. Distinct locations within the body relate to dissimilar microenvironments, which likely influence different responses to stimuli and to repair mechanisms.

In summary, multiple aspects of tendon physiology in combinatorial strategies have been explored in the context of tendon TERM. The combination of both biomechanical and biochemical cues has been shown to produce biomimetic tendon scaffolds from nano- to macro-scales, although the optimal strategy to achieve tendon regeneration continues an unmet research and clinical need. The recreation of tendon niche complexity demands for the assessment of suitable cellular and environmental conditions and for the development of more sophisticated tendon substitutes with improved tenogenic functions for therapeutic application in tendon pathologies.

Acknowledgments Authors acknowledge the project "Accelerating tissue engineering and personalized medicine discoveries by the integration of key enabling nanotechnologies, marinederived biomaterials and stem cells," supported by Norte Portugal Regional Operational Programme (NORTE 2020), under the Portugal 2020 Partnership Agreement, through the European Regional Development Fund (ERDF).

Authors acknowledge the H2020 Achilles Twinning Project No. 810850, and also the European Research Council CoG MagTendon No. 772817, and the FCT Project MagTT PTDC/CTM-CTM/ 29930/2017 (POCI-01-0145-FEDER-29930). 


\section{References}

Almeida H, Domingues RMA, Mithieux SM, Pires RA, Gonçalves AI, Gómez-Florit M, Reis RL, Weiss AS, Gomes ME (2019) Tropoelastin-coated tendon biomimetic scaffolds promote stem cell Tenogenic commitment and deposition of elastin-rich matrix. ACS Appl Mater Interfaces 11(22):19830-19840

Baldwin M, Snelling S, Dakin S, Carr A (2018) Augmenting endogenous repair of soft tissues with nanofibre scaffolds. J R Soc Interface 15(141)

Barber JG, Handorf AM, Allee TJ, Li WJ (2013) Braided nanofibrous scaffold for tendon and ligament tissue engineering. Tissue Eng Part A 19(11-12):1265-1274

Barsby T, Guest D (2013) Transforming growth factor Beta3 promotes tendon differentiation of equine embryo-derived stem cells. Tissue Eng A 19(19-20):2156-2165

Bashur CA, Shaffer RD, Dahlgren LA, Guelcher SA, Goldstein AS (2009) Effect of fiber diameter and alignment of electrospun polyurethane meshes on mesenchymal progenitor cells. Tissue Eng Part A 15(9):2435-2445

Bi Y, Ehirchiou D, Kilts TM, Inkson CA, Embree MC, Sonoyama W, Li L, Leet AI, Seo BM, Zhang L, Shi S, Young MF (2007) Identification of tendon stem/progenitor cells and the role of the extracellular matrix in their niche. Nat Med 13(10):1219-1227

Bracaglia LG, Smith BT, Watson E, Arumugasaamy N, Mikos AG, Fisher JP (2017) 3D printing for the design and fabrication of polymer-based gradient scaffolds. Acta Biomater 56:3-13

Brennan DA, Conte AA, Kanski G, Turkula S, Hu X, Kleiner MT, Beachley V (2018) Mechanical considerations for electrospun nanofibers in tendon and ligament repair. Adv Healthc Mater 7(12):e1701277

Brent AE, Schweitzer R, Tabin CJ (2003) A somitic compartment of tendon progenitors. Cell 113(2):235-248

Cadby JA, Buehler E, Godbout C, van Weeren PR, Snedeker JG (2014) Differences between the cell populations from the peritenon and the tendon core with regard to their potential implication in tendon repair. PLoS One 9(3):e92474

Chainani A, Hippensteel KJ, Kishan A, Garrigues NW, Ruch DS, Guilak F, Little D (2013) Multilayered electrospun scaffolds for tendon tissue engineering. Tissue Eng Part A 19(2324):2594-2604

Cheng X, Tsao C, Sylvia VL, Cornet D, Nicolella DP, Bredbenner TL, Christy RJ (2014) Plateletderived growth-factor-releasing aligned collagen-nanoparticle fibers promote the proliferation and tenogenic differentiation of adipose-derived stem cells. Acta Bio 10(3):1360-1369

Czaplewski SK, Tsai TL, Duenwald-Kuehl SE, Vanderby R Jr, Li WJ (2014) Tenogenic differentiation of human induced pluripotent stem cell-derived mesenchymal stem cells dictated by properties of braided submicron fibrous scaffolds. Biomaterials 35(25):6907-6917

Dalby MJ, García AJ, Salmeron-Sanchez M (2018) Receptor control in mesenchymal stem cell engineering. Nat Rev Mater 3:17091

Dale TP, Mazher S, Webb WR, Zhou J, Maffulli N, Chen GQ, El Haj AJ, Forsyth NR (2018) Tenogenic differentiation of human embryonic stem cells. Tissue Eng Part A 24(5-6):361-368

de Aro AA, Vidal BD, Pimentel ER (2012) Biochemical and anisotropical properties of tendons. Micron 43(2-3):205-214

de Mos M, Koevoet WJ, Jahr H, Verstegen MM, Heijboer MP, Kops N, van Leeuwen JP, Weinans H, Verhaar JA, van Osch GJ (2007) Intrinsic differentiation potential of adolescent human tendon tissue: an in-vitro cell differentiation study. BMC Musculoskelet Disord 8:16

Derakhshanfar S, Mbeleck R, Xu K, Zhang X, Zhong W, Xing M (2018) 3D bioprinting for biomedical devices and tissue engineering: a review of recent trends and advances. Bioact Mater 3(2):144-156

Docheva D, Muller SA, Majewski M, Evans CH (2015) Biologics for tendon repair. Adv Drug Deliv Rev 84:222-239 
Domingues RM, Chiera S, Gershovich P, Motta A, Reis RL, Gomes ME (2016) Enhancing the biomechanical performance of anisotropic Nanofibrous scaffolds in tendon tissue engineering: reinforcement with cellulose nanocrystals. Adv Healthc Mater 5(11):1364-1375

Dyment NA, Liu C-F, Kazemi N, Aschbacher-Smith LE, Kenter K, Breidenbach AP, Shearn JT, Wylie C, Rowe DW, Butler DL (2013) The paratenon contributes to scleraxis-expressing cells during patellar tendon healing. PLoS One 8(3):e59944

Engebretson B, Mussett ZR, Sikavitsas VI (2017) Tenocytic extract and mechanical stimulation in a tissue-engineered tendon construct increases cellular proliferation and ECM deposition. Biotechnol J 12(3):1-26

Engler AJ, Sen S, Sweeney HL, Discher DE (2006) Matrix elasticity directs stem cell lineage specification. Cell 126(4):677-689

English A, Azeem A, Spanoudes K, Jones E, Tripathi B, Basu N, McNamara K, Tofail SAM, Rooney N, Riley G, O'Riordan A, Cross G, Hutmacher D, Biggs M, Pandit A, Zeugolis DI (2015) Substrate topography: a valuable in vitro tool, but a clinical red herring for in vivo tenogenesis. Acta Biomater 27:3-12

Erisken C, Zhang X, Moffat KL, Levine WN, Lu HH (2013a) Scaffold fiber diameter regulates human tendon fibroblast growth and differentiation. Tissue Eng Part A 19(3-4):519-528

Erisken C, Zhang X, Moffat KL, Levine WN, Lu HH (2013b) Scaffold Fiber diameter regulates human tendon fibroblast growth and differentiation. Tissue Eng A 19(3-4):519-528

Farhat YM, Al-Maliki AA, Chen T, Juneja SC, Schwarz EM, O'Keefe RJ, Awad HA (2012) Gene expression analysis of the pleiotropic effects of TGF-beta 1 in an in vitro model of flexor tendon healing. PLoS One 7(12):12

Font Tellado S, Chiera S, Bonani W, Poh PSP, Migliaresi C, Motta A, Balmayor ER, van Griensven M (2018) Heparin functionalization increases retention of TGF- $\beta 2$ and GDF5 on biphasic silk fibroin scaffolds for tendon/ligament-to-bone tissue engineering. Acta Biomater 72:150-166

Freeman JW, Woods MD, Laurencin CT (2007) Tissue engineering of the anterior cruciate ligament using a braid - twist scaffold design. 40:2029-2036

Gilchrist CL, Ruch DS, Little D, Guilak F (2014) Micro-scale and meso-scale architectural cues cooperate and compete to direct aligned tissue formation. Biomaterials 35(38):10015-10024

Gonçalves AI, Rodrigues MT, Lee SJ, Atala A, Yoo JJ, Reis RL, Gomes ME (2013) Understanding the role of growth factors in modulating stem cell tenogenesis. PLoS One 8(12):e83734

Goncalves AI, Rodrigues MT, Carvalho PP, Banobre-Lopez M, Paz E, Freitas P, Gomes ME (2016) Exploring the potential of starch/Polycaprolactone aligned magnetic responsive scaffolds for tendon regeneration. Adv Healthc Mater 5(2):213-222

Gonçalves AI, Berdecka D, Rodrigues MT, Reis RL, Gomes ME (2018) Bioreactors for tendon tissue engineering: challenging mechanical demands towards tendon regeneration. Bioreactors for stem cell expansion and differentiation. CRC Press, Boca Raton, pp 269-300

Goncalves AI, Gershovich PM, Rodrigues MT, Reis RL, Gomes ME (2018a) Human adipose tissue-derived tenomodulin positive subpopulation of stem cells: a promising source of tendon progenitor cells. J Tissue Eng Regen Med 12(3):762-774

Goncalves AI, Rotherham M, Markides H, Rodrigues MT, Reis RL, Gomes ME, El Haj AJ (2018b) Triggering the activation of Activin a type II receptor in human adipose stem cells towards tenogenic commitment using mechanomagnetic stimulation. Nanomed Nanotechnol Biol Med 14(4):1149-1159

Goncalves AI, Berdecka D, Rodrigues MT, Eren AD, de Boer J, Reis RL, Gomes ME (2019) Evaluation of tenogenic differentiation potential of selected subpopulations of human adiposederived stem cells. J Tissue Eng Regen Med 13(12):2204-2217

Hakimi O, Mouthuy PA, Zargar N, Lostis E, Morrey M, Carr A (2015) A layered electrospun and woven surgical scaffold to enhance endogenous tendon repair. Acta Biomater 26:124-135

Havis E, Bonnin M-A, Olivera-Martinez I, Nazaret N, Ruggiu M, Weibel J, Durand C, Guerquin M-J, Bonod-Bidaud C, Ruggiero F (2014a) Transcriptomic analysis of mouse limb tendon cells during development. Development 141(19):3683-3696 
Havis E, Bonnin MA, Olivera-Martinez I, Nazaret N, Ruggiu M, Weibel J, Durand C, Guerquin MJ, Bonod-Bidaud C, Ruggiero F, Schweitzer R, Duprez D (2014b) Transcriptomic analysis of mouse limb tendon cells during development. Development 141(19):3683-3696

Havis E, Bonnin MA, de Lima JE, Charvet B, Milet C, Duprez D (2016) TGFbeta and FGF promote tendon progenitor fate and act downstream of muscle contraction to regulate tendon differentiation during chick limb development. Development 143(20):3839-3851

Izu Y, Ansorge HL, Zhang GY, Soslowsky LJ, Bonaldo P, Chu ML, Birk DE (2011) Dysfunctional tendon collagen fibrillogenesis in collagen VI null mice. Matrix Biol 30(1):53-61

Jayasree A, Kottappally Thankappan S, Ramachandran R, Sundaram MN, Chen C-H, Mony U, Chen J-P, Jayakumar R (2019) Bioengineered braided micro-Nano (multiscale) fibrous scaffolds for tendon reconstruction. ACS Biomater Sci Eng 5(3):1476-1486

Jenkins TL, Little D (2019) Synthetic scaffolds for musculoskeletal tissue engineering: cellular responses to fiber parameters. npj Regen Med 4(1):1-14

Katsura T, Tohyama H, Kondo E, Kitamura N, Yasuda K (2006) Effects of administration of transforming growth factor (TGF)-betal and anti-TGF-betal antibody on the mechanical properties of the stress-shielded patellar tendon. J Biomech 39(14):2566-2572

Killian ML, Cavinatto L, Galatz LM, Thomopoulos S (2012) The role of mechanobiology in tendon healing. J Shoulder Elb Surg 21(2):228-237

Kishore V, Bullock W, Sun X, Van Dyke WS, Akkus O (2012) Tenogenic differentiation of human MSCs induced by the topography of electrochemically aligned collagen threads. Biomaterials 33(7):2137-2144

Laranjeira M, Domingues RMA, Costa-Almeida R, Reis RL, Gomes ME (2017) 3D mimicry of native-tissue-Fiber architecture guides tendon-derived cells and adipose stem cells into artificial tendon constructs. Small 13(31)

Laternser S, Keller H, Leupin O, Rausch M, Graf-Hausner U, Rimann M (2018) A novel microplate 3D bioprinting platform for the engineering of muscle and tendon tissues. SLAS Technol 23(6):599-613

Lavagnino M, Wall ME, Little D, Banes AJ, Guilak F, Arnoczky SP (2015) Tendon Mechanobiology: current knowledge and future research opportunities. J Orthop Res 33(6):813-822

Lee CH, Yang G, Mao JJ, Lee CH, Lee FY, Tarafder S, Kao K, Jun Y, Yang G, Mao JJ (2015) Harnessing endogenous stem/progenitor cells for tendon regeneration find the latest version: harnessing endogenous stem/progenitor cells for tendon regeneration. 125(7):2690-2701

Lee NM, Erisken C, Iskratsch T, Sheetz M, Levine WN, Lu HH (2017) Polymer fiber-based models of connective tissue repair and healing. Biomaterials 112:303-312

Leung M, Jana S, Tsao C-T, Zhang M (2013) Tenogenic differentiation of human bone marrow stem cells via a combinatory effect of aligned chitosan-poly-caprolactone nanofibers and TGF- $\beta 3$. J Mater Chem B 1:6516-6524

Lim PN, Wang Z, Wang D, Konishi T, San Thian E (2017) Development in additive printing for tissue-engineered bone and tendon regeneration. Curr Opin Biomed Eng 2:99-104

Lin TW, Cardenas L, Soslowsky LJ (2004) Biomechanics of tendon injury and repair. J Biomech 37(6):865-877

Lin J, Zhou W, Han S, Bunpetch V, Zhao K, Liu C, Yin Z, Ouyang H (2018) Cell-material interactions in tendon tissue engineering. Acta Biomater 70:1-11

Lipman K, Wang CC, Ting K, Soo C, Zheng Z (2018) Tendinopathy: injury, repair, and current exploration. Drug Des Devel Ther 12:591-603

Liu HH, Zhang C, Zhu SA, Lu P, Zhu T, Gong XN, Zhang ZW, Hu JJ, Yin Z, Heng BC, Chen X, Ouyang HW (2015) Mohawk promotes the Tenogenesis of mesenchymal stem cells through activation of the TGF beta signaling pathway. Stem Cells 33(2):443-455

Madhurakkat Perikamana SK, Lee J, Ahmad T, Kim EM, Byun H, Lee S, Shin H (2018) Harnessing biochemical and structural cues for tenogenic differentiation of adipose derived stem cells (ADSCs) and development of an in vitro tissue interface mimicking tendon-bone insertion graft. Biomaterials 165:79-93 
Maeda T, Sakabe T, Sunaga A, Sakai K, Rivera AL, Keene DR, Sasaki T, Stavnezer E, Iannotti J, Schweitzer R, Ilic D, Baskaran H, Sakai T (2011) Conversion of mechanical force into TGFbeta-mediated biochemical signals. Curr Biol 21(11):933-941

Magnusson SP, Hansen P, Kjaer M (2003) Tendon properties in relation to muscular activity and physical training. Scand J Med Sci Sports 13(4):211-223

Merceron TK, Burt M, Seol YJ, Kang HW, Lee SJ, Yoo JJ, Atala A (2015) A 3D bioprinted complex structure for engineering the muscle-tendon unit. Biofabrication 7(3):035003

Mienaltowski MJ, Adams SM, Birk DE (2014) Tendon proper- and peritenon-derived progenitor cells have unique tenogenic properties. Stem Cell Res Ther 5(4):86

Mihaila SM, Frias AM, Pirraco RP, Rada T, Reis RL, Gomes ME, Marques AP (2013) Human adipose tissue-derived SSEA-4 subpopulation multi-differentiation potential towards the endothelial and osteogenic lineages. Tissue Eng Part A 19(1-2):235-246

Mihaila SM, Gaharwar AK, Reis RL, Khademhosseini A, Marques AP, Gomes ME (2014) The osteogenic differentiation of SSEA-4 sub-population of human adipose derived stem cells using silicate nanoplatelets. Biomaterials 35(33):9087-9099

Mihaila SM, Resende MF, Reis RL, Gomes ME, Marques AP (2015) Interactive endothelial phenotype maintenance and osteogenic differentiation of adipose tissue stromal vascular fraction SSEA-4+-derived cells. J Tissue Eng Regen Med

Millar NL, Gilchrist DS, Akbar M, Reilly JH, Kerr SC, Campbell AL, Murrell GAC, Liew FY, Kurowska-Stolarska M, McInnes IB (2015) MicroRNA29a regulates IL-33-mediated tissue remodelling in tendon disease. Nat Commun 6:13

Min HK, Oh SH, Lee JM, Im GI, Lee JH (2014) Porous membrane with reverse gradients of PDGFBB and BMP-2 for tendon-to-bone repair: in vitro evaluation on adipose-derived stem cell differentiation. Acta Biomater 10(3):1272-1279

Miranda-Nieves D, Chaikof EL (2017) Collagen and elastin biomaterials for the fabrication of engineered living tissues. ACS Biomater Sci Eng 3(5):694-711

Miranville A, Heeschen C, Sengenes C, Curat CA, Busse R, Bouloumie A (2004) Improvement of postnatal neovascularization by human adipose tissue-derived stem cells. Circulation 110 (3):349-355

Moffat KL, Kwei ASP, Spalazzi JP, Doty SB, Levine WN, Lu HH (2009) Novel nanofiber-based scaffold for rotator cuff repair and augmentation. Tissue Eng A 15(1):115-126

Moroni L, Boland T, Burdick JA, De Maria C, Derby B, Forgacs G, Groll J, Li Q, Malda J, Mironov VA, Mota C, Nakamura M, Shu W, Takeuchi S, Woodfield TBF, Xu T, Yoo JJ, Vozzi G (2018a) Biofabrication: a guide to technology and terminology. Trends Biotechnol 36(4):384-402

Moroni L, Burdick JA, Highley C, Lee SJ, Morimoto Y, Takeuchi S, Yoo JJ (2018b) Biofabrication strategies for 3D in vitro models and regenerative medicine. Nat Rev Mater 3:5

Muller SA, Evans CH, Heisterbach PE, Majewski M (2018) The role of the Paratenon in Achilles tendon healing: a study in rats. Am J Sports Med 46(5):1214-1219

Orr SB, Chainani A, Hippensteel KJ, Kishan A, Gilchrist C, Garrigues NW, Ruch DS, Guilak F, Little D (2015) Aligned multilayered electrospun scaffolds for rotator cuff tendon tissue engineering. Acta Biomater 24:117-126

Park SH, Choi YJ, Moon SW, Lee BH, Shim JH, Cho DW, Wang JH (2018) Three-dimensional bioprinted scaffold sleeves with mesenchymal stem cells for enhancement of tendon-to-bone healing in anterior cruciate ligament reconstruction using soft-tissue tendon graft. Arthroscopy 34(1):166-179

Pauly HM, Sathy BN, Olvera D, McCarthy HO, Kelly DJ, Popat KC, Dunne NJ, Haut Donahue TL (2017) Hierarchically structured electrospun scaffolds with chemically conjugated growth factor for ligament tissue engineering. Tissue Eng Part A 23(15-16):823-836

Perucca Orfei C, Vigano M, Pearson JR, Colombini A, De Luca P, Ragni E, Santos-Ruiz L, de Girolamo L (2019) In vitro induction of tendon-specific markers in tendon cells, adipose- and bone marrow-derived stem cells is dependent on TGFbeta3, BMP-12 and ascorbic acid stimulation. Int J Mol Sci 20(1) 
Qin TW, Yang ZM, Wu ZZ, Xie HQ, Qin J, Cai SX (2005) Adhesion strength of human tenocytes to extracellular matrix component-modified poly(DL-lactide-co-glycolide) substrates. Biomaterials 26(33):6635-6642

Rada T, Gomes ME, Reis RL (2011a) A novel method for the isolation of subpopulations of rat adipose stem cells with different proliferation and osteogenic differentiation potentials. J Tissue Eng Regen Med 5(8):655-664

Rada T, Reis RL, Gomes ME (2011b) Distinct stem cells subpopulations isolated from human adipose tissue exhibit different chondrogenic and osteogenic differentiation potential. Stem Cell Rev 7(1):64-76

Rada T, Santos TC, Marques AP, Correlo VM, Frias AM, Castro AG, Neves NM, Gomes ME, Reis RL (2012) Osteogenic differentiation of two distinct subpopulations of human adipose-derived stem cells: an in vitro and in vivo study. J Tissue Eng Regen Med 6(1):1-11

Rees JD, Wilson AM, Wolman RL (2006) Current concepts in the management of tendon disorders. Rheumatology 45(5):508-521

Riehl BD, Park JH, Kwon IK, Lim JY (2012) Mechanical stretching for tissue engineering: twodimensional and three-dimensional constructs. Tissue Eng Part B Rev 18(4):288-300

Riley G (2004) The pathogenesis of tendinopathy. A molecular perspective. Rheumatology 43(2):131-142

Rinoldi C, Costantini M, Kijeńska-Gawrońska E, Testa S, Fornetti E, Heljak M, Ćwiklińska M, Buda R, Baldi J, Cannata S, Guzowski J, Gargioli C, Khademhosseini A, Swieszkowski W (2019) Tendon tissue engineering: effects of mechanical and biochemical stimulation on stem cell alignment on cell-laden hydrogel yarns. Adv Healthc Mater 8(7):1-10

Rodrigues MT, Reis RL, Gomes ME (2013) Engineering tendon and ligament tissues: present developments towards successful clinical products. J Tissue Eng Regen Med 7(9):673-686

Rothrauff BB, Lauro BB, Yang G, Debski RE, Musahl V, Tuan RS (2017) Braided and stacked electrospun Nanofibrous scaffolds for tendon and ligament tissue engineering. Tissue Eng Part A 23(9-10):378-389

Sahoo S, Toh SL, Goh JCH (2010) A bFGF-releasing silk/PLGA-based biohybrid scaffold for ligament/tendon tissue engineering using mesenchymal progenitor cells. Biomaterials 31(11):2990-2998

Salingcarnboriboon R, Yoshitake H, Tsuji K, Obinata M, Amagasa T, Nifuji A, Noda M (2003) Establishment of tendon-derived cell lines exhibiting pluripotent mesenchymal stem cell-like property. Exp Cell Res 287(2):289-300

Santos LJ, Reis RL, Gomes ME (2015) Harnessing magnetic-mechano actuation in regenerative medicine and tissue engineering. Trends Biotechnol 33(8):471-479

Santos ML, Rodrigues MT, Domingues RM, Reis RL, Gomes ME (2017) Biomaterials as tendon and ligament substitutes: current developments. In: Regenerative strategies for the treatment of knee joint disabilities, vol 21. Springer, pp 349-371

Schmierer B, Hill CS (2007) TGF beta-SMAD signal transduction: molecular specificity and functional flexibility. Nat Rev Mol Cell Biol 8(12):970-982

Schneider M, Angele P, Jarvinen TAH, Docheva D (2017) Rescue plan for Achilles: therapeutics steering the fate and functions of stem cells in tendon wound healing. Adv Drug Deliv Rev

Schoenenberger AD, Foolen J, Moor P, Silvan U, Snedeker JG (2018) Substrate fiber alignment mediates tendon cell response to inflammatory signaling. Acta Biomater 71:306-317

Screen HRC, Berk DE, Kadler KE, Ramirez F, Young MF (2015) Tendon Functional Extracellular Matrix. J Orthop Res 33(6):793-799

Sengenes C, Miranville A, Maumus M, de Barros S, Busse R, Bouloumie A (2007) Chemotaxis and differentiation of human adipose tissue $\mathrm{CD} 34+/ \mathrm{CD} 31$ - progenitor cells: role of stromal derived factor-1 released by adipose tissue capillary endothelial cells. Stem Cells 25(9):2269-2276

Sharma P, Maffulli N (2005) Current concepts review tendon injury and tendinopathy: healing and repair. J Bone Joint Surg Am 87A(1):187-202

Sharma P, Maffulli N (2006) Biology of tendon injury: healing, modeling and remodeling. J Musculoskelet Nueronal Interact 6(2):181 
Sharma RI, Snedeker JG (2010) Biochemical and biomechanical gradients for directed bone marrow stromal cell differentiation toward tendon and bone. Biomaterials 31(30):7695-7704

Shen H, Gelberman RH, Silva MJ, Sakiyama-Elbert SE, Thomopoulos S (2013) BMP12 induces tenogenic differentiation of adipose-derived stromal cells. PLoS One 8(10):1-14

Shen H, Jayaram R, Yoneda S, Linderman SW, Sakiyama-Elbert SE, Xia Y, Gelberman RH, Thomopoulos S (2018) The effect of adipose-derived stem cell sheets and CTGF on early flexor tendon healing in a canine model. Sci Rep 8(1):11078

Soslowsky LJ, Thomopoulos S, Tun S, Flanagan CL, Keefer CC, Mastaw J, Carpenter JE (2000) Neer award 1999 - overuse activity injures the supraspinatus tendon in an animal model: a histologic and biomechanical study. J Shoulder Elb Surg 9(2):79-84

Spanoudes K, Gaspar D, Pandit A, Zeugolis DI (2014) The biophysical, biochemical, and biological toolbox for tenogenic phenotype maintenance in vitro. Trends Biotechnol 32(9):474-482

Stanco D, Caprara C, Ciardelli G, Mariotta L, Gola M, Minonzio G, Soldati G (2019) Tenogenic differentiation protocol in xenogenic-free media enhances tendon-related marker expression in ASCs. PLoS One 14(2)

Subramony SD, Dargis BR, Castillo M, Azeloglu EU, Tracey MS, Su A, Lu HH (2013) The guidance of stem cell differentiation by substrate alignment and mechanical stimulation. Biomaterials 34(8):1942-1953

Theisen C, Fuchs-Winkelmann S, Knappstein K, Efe T, Schmitt J, Paletta JRJ, Schofer MD (2010) Influence of nanofibers on growth and gene expression of human tendon derived fibroblast. Biomed Eng Online 9:1-12

Tomás AR, Gonçalves AI, Paz E, Freitas PP, Domingues RMA, Gomes ME (2019) Magnetomechanical actuation of magnetic responsive fibrous scaffolds boosts Tenogenesis of human adipose stem cells. Nanoscale

Tong WY, Shen W, Yeung CW, Zhao Y, Cheng SH, Chu PK, Chan D, Chan GC, Cheung KM, Yeung KW, Lam YW (2012) Functional replication of the tendon tissue microenvironment by a bioimprinted substrate and the support of tenocytic differentiation of mesenchymal stem cells. Biomaterials 33(31):7686-7698

Vining KH, Mooney DJ (2017) Mechanical forces direct stem cell behaviour in development and regeneration. Nat Rev Mol Cell Biol 18(12):728-742

Wakefield LM, Hill CS (2013) Beyond TGF beta: roles of other TGF beta superfamily members in cancer. Nat Rev Cancer 13(5):328-341

Wang JH-C (2006) Mechanobiology of tendon. J Biomech 39(9):1563-1582

Wang JHC, Guo QP, Li B (2012) Tendon biomechanics and Mechanobiology-A Minireview of basic concepts and recent advancements. J Hand Ther 25(2):133-140

Wang T, Gardiner BS, Lin Z, Rubenson J, Kirk TB, Wang A, Xu J, Smith DW, Lloyd DG, Zheng MH (2013) Bioreactor Design for Tendon/ligament engineering. Tissue Eng Part B Rev 19(2): 133-146

Wenstrup RJ, Florer JB, Brunskill EW, Bell SM, Chervoneva I, Birk DE (2004) Type V collagen controls the initiation of collagen fibril assembly. J Biol Chem 279(51):53331-53337

Willett TL, Labow RS, Avery NC, Lee JM (2007) Increased proteolysis of collagen in an in vitro tensile overload tendon model. Ann Biomed Eng 35(11):1961-1972

Woo SLY, Hildebrand K, Watanabe N, Fenwick JA, Papageorgiou CD, Wang JHC (1999) Tissue engineering of ligament and tendon healing. Clin Orthop Relat Res 367:S312-S323

Wrighton KH, Lin X, Feng XH (2009) Phospho-control of TGF-beta superfamily signaling. Cell Res 19(1):8-20

Wu S, Wang Y, Streubel PN, Duan B (2017) Living nanofiber yarn-based woven biotextiles for tendon tissue engineering using cell tri-culture and mechanical stimulation. Acta Biomater 62:102-115

Xie J, Li X, Lipner J, Manning CN, Schwartz AG, Thomopoulos S, Xia Y (2010) "Aligned-torandom" nanofiber scaffolds for mimicking the structure of the tendon-to-bone insertion site. Nanoscale 2(6):923-923 
Yang G, Rothrauff BB, Lin H, Gottardi R, Alexander PG, Tuan RS (2013) Enhancement of tenogenic differentiation of human adipose stem cells by tendon-derived extracellular matrix. Biomaterials 34:9295-9306

Yang G, Lin H, Rothrauff BB, Yu S, Tuan RS (2016) Multilayered polycaprolactone/gelatin fiberhydrogel composite for tendon tissue engineering. Acta Biomater 35:68-76

Yang G, Rothrauff BB, Lin H, Yu S, Tuan RS (2017) Tendon-derived extracellular matrix enhances transforming growth factor- $\beta 3$-induced Tenogenic differentiation of human adipose-derived stem cells. Tissue Eng A 23(3-4):166-176

Yin Z, Guo J, Wu TY, Chen X, Xu LL, Lin SE, Sun YX, Chan KM, Ouyang H, Li G (2016) Stepwise differentiation of mesenchymal stem cells augments tendon-like tissue formation and defect repair in vivo. Stem Cells Transl Med 5(8):1106-1116

Younesi M, Islam A, Kishore V, Anderson JM, Akkus O (2014) Tenogenic induction of human MSCs by Anisotropically aligned collagen biotextiles. Adv Funct Mater 24(36):5762-5770

Yu H, Lim KP, Xiong S, Tan LP, Shim W (2013) Functional morphometric analysis in cellular behaviors: shape and size matter. Adv Healthc Mater 2(9):1188-1197

Zhang J, Wang JH-C (2010) Characterization of differential properties of rabbit tendon stem cells and tenocytes. BMC Musculoskelet Disord 11:10

Zhang C, Yuan H, Liu H, Chen X, Lu P, Zhu T, Yang L, Yin Z, Heng BC, Zhang Y, Ouyang H (2015) Well-aligned chitosan-based ultrafine fibers committed Teno-lineage differentiation of human induced pluripotent stem cells for Achilles tendon regeneration. Biomaterials $53: 716-730$

Zhang YJ, Chen X, Li G, Chan KM, Heng BC, Yin Z, Ouyang HW (2018a) Concise review: stem cell fate guided by bioactive molecules for tendon regeneration. Stem Cells Transl Med 7(5):404-414

Zhang H, Liu M-F, Liu R-C, Shen W-L, Yin Z, Chen X (2018b) Physical microenvironment-based inducible scaffold for stem cell differentiation and tendon regeneration. Tissue Eng Part B Rev 24(6):443-453

Zhang C, Wang X, Zhang E, Yang L, Yuan H, Tu W, Zhang H, Yin Z, Shen W, Chen X, Zhang Y, Ouyang H (2018c) An epigenetic bioactive composite scaffold with well-aligned nanofibers for functional tendon tissue engineering. Acta Biomater 66:141-156

Zhao X, Jiang SC, Liu S, Chen S, Lin ZY, Pan GQ, He F, Li FF, Fan CY, Cui WG (2015) Optimization of intrinsic and extrinsic tendon healing through controllable water-soluble mitomycin- $\mathrm{C}$ release from electrospun fibers by mediating adhesion-related gene expression. Biomaterials 61:61-74

Zheng Z, Ran J, Chen W, Hu Y, Zhu T, Chen X, Yin Z, Heng BC, Feng G, Le H, Tang C, Huang J, Chen Y, Zhou Y, Dominique P, Shen W, Ouyang HW (2017) Alignment of collagen fiber in knitted silk scaffold for functional massive rotator cuff repair. Acta Biomater 51:317-329 